\title{
EM BUSCA DE NOVOS IMAGINÁRIOS SOCIAIS: DIREITOS FUNDAMENTAIS E UTOPIAS POLÍTICAS A PARTIR DE DRUCILLA CORNELL
}

IN SEARCH OF NEW SOCIAL IMAGINARIES: BASIC RIGHTS AND POLITICAL UTOPIES IN DRUCILLA CORNELL

EN BUSCA DE NUEVOS IMAGINARIOS SOCIALES: DERECHOS FUNDAMENTALES Y UTOPIAS POLÍTICAS A PARTIR DE DRUCILLA CORNELL

\section{Leonardo Monteiro Crespo de Almeida ${ }^{1}$}

Licença CC BY:

Artigo distribuído sob os termos Creative

Commons, permite uso e distribuição irrestrita em qualquer meio desde que o autor credite a fonte original.

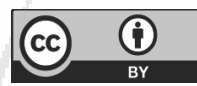

Resumo: A pretensão deste artigo reside em esclarecer possíveis relações entre o conceito de domínio imaginário proposto por Drucilla Cornell e direitos fundamentais tendo em vista as lutas por transformações sociais empreendidas por diversos grupos minoritários. $\mathrm{O}$ artigo toma como fio condutor o desenvolvimento do conceito de domínio imaginário tendo como principal eixo de referência as lutas políticas pelo reconhecimento de novos direitos e formas de integração social. Nesta direção, o artigo sustenta que o conceito pode ser útil para ilustrar a dimensão prospectiva que envolve as lutas políticas, trazendo consigo novas imagens e interpretações sobre os valores institucionais centrais para a comunidade. Essa linha de argumentação é fortalecida através de uma justaposição das considerações de Cornell com as de Chantal Mouffe e Cornelius Castoriadis referentes à temática em estudo. A pesquisa fora realizada através de uma revisão de literatura.

Palavras-chave: Drucilla Cornell; Democracia; Agonismo; Direitos Fundamentais.

Abstract: The main objective of this article is to clarify possible relations between the concept of imaginary domain introduced by Drucilla Cornell and basic rights in the struggles of diverse minorities for social transformation. The guidewire for this article is the development of the concept of imaginary domain through the political struggles for recognition of new rights and forms of social integration. This article, therefore, defends the view that this concept may be useful for indicating a prospective dimension related to political struggles, in which new images and interpretations of the central values

1 Doutor e Mestre em Direito pela Universidade Federal de Pernambuco/UFPE. Bacharel em Filosofia pela Universidade Federal de Pernambuco/UFPE. É professor da graduação e pós-graduação de Direito da Faculdade Damas da Instrução Cristã (FADIC), professor substituto na Faculdade de Direito do Recife/UFPE, professor da graduação do curso de Direito da Faculdade Católica Imaculada Conceição do Recife/FICR. Reside em Recife Pernambuco. E-mail: leonardoalmeida326@gmail.com. 
of the community can be made. This line of reasoning is reinforced through a juxtaposition of Cornell's remarks and those of Chantal Mouffe and Cornelius Castoriadis in relation to the main thesis of this article. The methodological approach used in this research is a literature review.

Keywords: Drucilla Cornell; Democracy; Agonism; Basic Rights.

Resumen: La pretensión de este artículo reside en esclarecer posibles relaciones entre el concepto de dominio imaginario propuesto por Drucilla Cornell y derechos fundamentales ante las luchas por transformaciones sociales emprendidas por diversos grupos minoritarios. El artículo toma como hilo conductor el desarrollo del concepto de dominio imaginario teniendo como principal eje de referencia las luchas políticas por el reconocimiento de nuevos derechos y formas de integración social. En esta dirección, el artículo sustenta que el concepto puede ser útil para ilustrar la dimensión prospectiva que envuelven las luchas políticas, trayendo consigo nuevas imágenes e interpretaciones sobre los valores institucionales centrales para la comunidad. Esa línea de argumentación es fortalecida a través de una yuxtaposición de las consideraciones de Cornell con las de Chantal Mouffe y Cornelius Castoriadis referentes a la temática en estudio. La investigación fue realizada a través de una revisión de literatura.

Palabras clave: Drucilla Cornell; Democracia; Agonismo; Derechos Fundamentales.

\section{INTRODUÇÃO}

Para além da proteção das prerrogativas básicas que permitem aos cidadãos exercer prática política e a realização particular dos seus projetos de vida individuais, os direitos fundamentais trazem implicitamente uma imagem de sociedade ancorada em uma constelação de valores que norteiam esses direitos. Valores como liberdade, igualdade, privacidade não só integram as suas respectivas garantias jurídicas respaldadas pelos direitos fundamentais, como estabelecem direcionamentos para transformações institucionais, a exemplo de políticas públicas, projetos de lei e mesmo atuação dos tribunais superiores, quando cabível. Esses valores ilustram, ainda que de maneira difusa e abrangente, uma imagem de sociedade que, não sendo plenamente atualizada, integra o funcionamento usual das práticas institucionais.

As sociedades democráticas liberais carregam consigo o compromisso de promover a possibilidade da participação livre e igualitária dos cidadãos na construção de uma comunidade que surge como projeto coletivo comum. Uma primeira característica dessas sociedades, no entanto, reside na pluralidade crescente de pontos de vista e perspectivas distintas em torno do significado e da abrangência dos valores fundamentais. Compreensões diferentes dos valores proporcionam, por sua vez, imagens diversas do modelo social o qual se pretende alcançar.

Em uma dada concepção, por exemplo, a promoção da liberdade pode vir a ser confundida, ou mesmo integralmente assimilada, à defesa irrestrita do livre-mercado e da intervenção mínima do Estado no domínio econômico, eventualmente trazendo consigo também uma relutância em se construir uma rede de proteção social. A autonomia individual passa a ser identificada com a 
responsabilização individual e com não-interferência do Estado na promoção de uma ou outra forma de vida adequada. Uma outra perspectiva, porém, pode ampliar a noção de autonomia para a realização dos projetos individuais de cada um, com isso pressionando um maior comprometimento do poder político em proporcionar as condições materiais que tornarão viável essa realização. Nela o mercado deixa de ser a única referência a ser considerada na avaliação das transformações sociais e do grau de prosperidade a que se pode alcançar.

Nas diferenças subjacentes às várias concepções de sociedade vistas como adequadas, o pluralismo surge como uma condição incontornável que amplia problemas que vão desde a alocação mais adequada para os recursos materiais da sociedade, haja vista a persistente desigualdade econômica das sociedades capitalistas, até as novas formas de integração social de grupos outrora marginalizados, seja do ponto de vista econômico ou em termos de representação nos diversos espaços da sociedade.

As visões concorrentes de sociedades, uma vez ancoradas em interpretações específicas sobre valores, interferem diretamente na maneira com que os direitos fundamentais serão historicamente promovidos e qual a extensão dessas promoções². É nesse horizonte que se desenvolvem debates sobre temas cruciais para uma maior ou menor efetivação desses direitos: discussões sobre cotas, sobre ampliação ou redução do porte de armas de fogo, da tipificação penal de condutas ofensiva a homossexuais e outras minorias. Neste ponto, os direitos fundamentais positivos se tornam um campo de batalha no qual diferentes grupos lutam para fixar, mesmo que temporariamente, as suas visões particulares como corretas também para os grupos remanescentes.

Há décadas Drucilla Cornell, professora emérita do departamento de ciência política, literatura comparada e estudos de gênero da Universidade de Rutgers, vem realizando um trabalho no qual críticas filosóficas se fundem a investigações jurídicas que confrontam os limites e as possibilidades presentes nas democracias recentes. Sua obra é atravessada por um interesse constante sobre o potencial de transformação social em direção a uma sociedade que, sendo mais igualitária, é também sensível à singularidade de cada indivíduo e de segmentos minoritários do social.

Se o diagnóstico das injustiças e patologias sociais assume uma dimensão polêmica, assim procede para introduzir nessas questões reflexões morais que muitas vezes tendem a permanecer na periferia dessas formas de indagação. Por mais difícil e complexa que seja essa investigação, é preciso ao menos tentar vislumbrar no presente, por vezes atravessado por injustiças e diversas formas de violência, possibilidades de uma sociedade mais solidária na qual essas circunstâncias não sejam mais aceitas.

O propósito deste artigo é o de esclarecer a maneira como Cornell desenvolve o seu conceito de imaginário e de que maneira essa abordagem pode ser produtiva para uma reflexão filosófica em torno do potencial político e transformador dos direitos fundamentais. Se, por um lado, a

2 Cf. BOBBIO, Norberto. A Era dos Direitos. Rio de Janeiro: Campus, 1992, p. 5 e ss. 
normatividade jurídica pode produzir ou mesmo respaldar formas sistêmicas de opressão, é também através dela que os anseios por justiça e transformação encontram um suporte institucional que lhes permitem alguma forma de materialização no plano social.

Tomando como fio condutor o modo pelo qual a autora problematiza a condição feminina em vários aspectos institucionais, a exemplo do aborto e da autonomia sobre o seu próprio corpo, este artigo pretende explorar e desenvolver analiticamente a maneira como o imaginário social se encontram articulados aos direitos fundamentais e de que maneira isso é significativo para o projeto político que propõem ${ }^{3}$. Considerando a orientação normativa do trabalho de Cornell, é de grande importância investigar os pressupostos que informam aqueles projetos porque são neles que se pode discernir obstáculos e orientações contrárias a uma maior representação e participação dos segmentos minoritários.

A reflexão moral que a autora desenvolve em torno da liberdade é atravessada por um ímpeto emancipatório comprometido em superar as diversas relações de opressão que impedem certos grupos de pôr em prática os seus projetos e anseios. Em circunstâncias como essa, os direitos fundamentais encontram barreiras institucionais que dificultam, ou mesmo impedem, o seu reconhecimento e implementação na vida de vários indivíduos que, por razões diversas, são tratados como cidadãos de menor valor. É neste ponto em que a reflexão moral da autora visa a identificar essas formas de constrangimentos institucional com o propósito de uma vez examinadas e denunciadas, serem também superadas.

Na primeira seção o artigo pretende apresentar e desenvolver a noção de domínio imaginário e a forma com que Cornell emprega o conceito para explorar o potencial emancipador latente no direito de moderno. A segunda seção, por sua vez, pretende associar o domínio imaginário aos direitos fundamentais. Por fim, a terceira seção pretende ilustrar as diversas formas pelas quais podem ser úteis para a concretização das demandas políticas dos grupos minoritários.

Muito embora o foco da revisão de literatura seja a obra de Drucilla Cornell abordada através de noções muito específicas, como o domínio imaginário, recorre-se a outros autores com o propósito de desenvolver e complementar alguns dos questionamentos teóricos suscitados pela autora, como Chantal Mouffe e Cornelius Castoriadis. Ambos são também abordados através do vínculo entre o político e o imaginário.

\section{O DOMÍNIO IMAGINÁRIO E AS TRANSFORMAÇÕES SOCIAIS: ABRINDO O FUTURO NO PRESENTE}

$\mathrm{Na}$ medida em que pretende resguardar e proteger prerrogativas, o direito traz consigo uma relação íntima e profunda com a temporalidade. Se a norma surge e existe em função de 3 Cf. BOBBIO, Norberto. A Era dos Direitos, p. 22 e ss. 
um futuro que se pretende controlar, mantendo-o em conformidade com a projeção que dele se faz antecipadamente, por outro lado a maneira pela qual a linguagem jurídica é constantemente deslocada e reinserida em novos contextos e circunstâncias os quais sequer foram cogitados, torna inviável uma plena conformidade. O que o direito pode fornecer é um panorama mais amplo no qual certas opções passadas podem ser revistas - e ressignificadas - à luz das transformações sociais contemporâneas. Essa é uma consideração relevante quando observados os valores fundamentais que norteiam as opções políticas da comunidade, a exemplo da liberdade e da igualdade que tradicionalmente serviram - e servem - de norte às democracias liberais ${ }^{4}$.

A democracia moderna estabelece um pano de fundo institucional no qual diversos ideais podem ser articulados em práticas políticas que, confrontando e questionando aspectos indesejáveis da realidade social, buscam resolvê-los. Em termos normativos, Aleksander Peczenik elenca o exercício do poder por legítimos representantes do povo, decisões tomadas de forma majoritária por esses representantes, a presença e o respeito pelos direitos humanos, a aplicação consistente e previsível das normas jurídicas que se materializa no Estado de Direito e a divisão de poderes, como elementos constitutivos das democracias liberais modernas ${ }^{5}$.

Todo esse arcabouço, em tese, concorre para a proteção da soberania popular ao mesmo tempo em que estabelece o respeito pelos direitos e garantias individuais. A expansão do poder popular e os direitos fundamentais se ajustam reciprocamente em uma relação circular: enquanto o poder popular permite a criação de novos direitos, estes atuam, por sua vez, restringindo e moldando as formas de mobilização popular. Dentre outros aspectos relevantes dessa limitação, é importante lembrar - e Cornell assim o faz - que mesmo a defesa dos ideais mais abrangentes e inclusivos pode trazer consigo potenciais de exclusão e opressão que não se mostram, a princípio, prontamente evidentes para quem os defende. Essa demarcação também traz implicações importantes para os referenciais normativos dos direitos humanos, como a ideia de humanidade, quando eles são contrapostos às diferentes maneiras pelas quais os ordenamentos jurídicos locais concebem a pessoa. Em síntese, sem um contínuo exercício de autocrítica e correção, mesmo os ideais mais sólidos que servem de fundamento para as práticas democráticas podem, dadas as circunstâncias, tornarem-se profundamente opressivos. Cornell observa:

De fato, mesmo o maior dos ideais, logo após ser articulado e defendido mesmo o ideal da humanidade - pode se tornar excludente no momento mesmo de sua defesa. Como muitos filósofos e teóricos contemporâneos observaram, normas podem normalizar e deslocar outros para fora da norma como anormais ou, pior ainda, fora do escopo da humanidade. De forma similar, alguns podem querer argumentar que porque os direitos podem legalmente incorporar certas concepções limitadas do ser humano na forma abstrata da pessoa, os direitos humanos negam a idealidade da humanidade e, além disso, essa negação se mostra inabalável nos sistemas jurídicos (Tradução do próprio autor) ${ }^{6}$.

4 Cf. BADER, Veit. Democratic inclusion in polities and governance arrangements. Constellations, v. 25, 2018, p. 572 e ss.

5 Cf. NERGELIUS, Joakin. Derecho y Democracia. Revista Doxa, v. 8, 1990, p. 311 e ss.

6 CORNELL, Drucilla. Defending Ideals: War, Democracy, and Political Struggles. London: Routledge, 2004, p. ix. 
A autora possui razões consideráveis para desenvolver essas preocupações uma vez que, à data de escrita desta obra, Defending Ideals, no ano de 2004, a administração do governo Bush já havia deflagrado a intervenção no Afeganistão e no Iraque, esta última sendo motivada pela necessidade de defesa dos Estados Unidos diante da posse de armas nucleares do governo iraquiano, o que se mostrou uma análise, no mínimo, equivocada. Como justificativa subsequente para contornar a ausência das armas, as razões de ordem humanitária e associadas à proteção dos direitos humanos do povo iraquiano foram enunciadas: muito embora o país não estivesse de posse do arsenal mencionado, a intervenção ainda assim é sustentável tendo como base o opressivo regime de Saddam Hussein e as violações recorrentes aos direitos fundamentais do povo iraquiano. Nesta circunstância, os direitos humanos foram convertidos em elementos que respaldam, ao invés de confrontarem, uma discutível intervenção de um país sobre o outro sem o devido amparo legal, nem mesmo um apoio internacional considerável.

Se os ideais podem ser apreendidos para respaldar práticas que, a princípio, eles se mostrariam incompatíveis, é mais uma razão para que se exerça uma vigilância crítica sobre eles. Admitindo que a defesa dos ideais é relevante, o que Cornell assente, então ela necessita ser também balanceada com uma atitude aberta e flexível diante da realidade social e histórica na qual esses ideais são pensados e discutidos. Essa atitude precisaria estar presente no exercício de uma autorreflexão coletiva na qual uma dada comunidade reconsidera os seus valores mais significativos de sua identidade, ajustando o atual estado de coisas com as expectativas que são despertadas por esses valores.

A fundamentação filosófica para essa atitude da parte de Cornell é, em larga escala, baseada na sua interpretação da terceira crítica de Kant, especialmente no tocante ao conceito de juízo reflexivo e a maneira pelo qual o esclarecimento é tomado como um processo de autorreflexão contínua e aberta ao invés de uma etapa a ser alcançada. Em discussão com John Brenkman sobre a obra The Law of Peoples de John Rawls, Cornell argumenta:

Em sua terceira Crítica, Kant finalmente nos mostra o porquê do Esclarecimento como um projeto teórico sistemático precisa permanecer incompleto. A compreensão do juízo reflexivo que Kant desenvolve nesta crítica não se volta para o domínio de nenhum objeto específico, a saber, objetos artísticos, mas para aquelas experiências do sujeito em que o prazer e a dor não se ajustam e nem podem se ajustar seja no mundo de objetos cognoscíveis ou na esfera da liberdade moral... Inexiste, em outras palavras, qualquer fechamento teórico pelo juízo reflexivo na brecha deixada pelas duas críticas entre os domínios do fato e do valor (Tradução do próprio autor) ${ }^{7}$.

Como a autora bem observa, Kant não está defendendo uma forma simples de esteticismo, circunscrevendo os valores ao âmbito puramente subjetivo. Os afetos, e com ele o juízo reflexivo, pode vir a aproximar a cisão entre fato/valor através de um senso comum estético (sensus communis

7 CORNELL, Drucilla. Enlightening the Enlightenment: A Response to John Brenkman. Critical Inquiry, v. 26, n. 1, 1999, p. 130. 
aestheticus) que se expressa em dever-ser enraizado em uma comunidade partilhada. Nesta comunidade cada indivíduo está articulado com o outro através das bases subjetivas do seu juízo reflexivo referente ao belo e ao sublime, acrescentando, esclarecendo e se deixando modificar por outras perspectivas. $O$ senso comum estético kantiano depende de uma autorreflexão contínua sobre si mesmo: não estando nem situado no domínio dos fatos, nem na esfera da liberdade, o senso comum estético aponta uma incompletude permanente. O público, então, é sempre algo a ser construído, pensando e repensado à luz de novas vivências que atravessam a existência corpórea dos indivíduos, os apresentando situações de dor e prazer. Em todo esse momento, como Cornell bem observa, a razão é confrontada com o seu outro, o afeto, e com ele também os prazeres e os sofrimentos.

O princípio da mentalidade ampliada (erweiterle Denkungsart) aponta para a superação dos limites da concepção individual em prol de uma perspectiva, um ponto de vista, que tem na humanidade a sua principal referência. Se, por um lado, não é viável abdicar das próprias crenças e convicções acerca dos valores referentes a comunidade em que se encontra situado, por outro lado é possível - e, diante do significativo pluralismo social, até necessário - pensar a comunidade como espaço de realização no qual projetos distintos podem ser igualmente realizados desde que não coloquem em risco a existência desse espaço em comum. Essa tensão é representada pela distinção kantiana, a ser retomada e amplamente discutida no debate entre liberais e comunitaristas, entre o bom e o justo, ou seja, entre as convicções pessoais sobre os valores e ideais norteadores da comunidade, e os princípios de abrangência geral que a todos envolvem.

A separação do bom e do justo pode ser nomeada como tese da descontinuidade e é discutida por Cornell em sua obra At The Heart of Freedom. O que é particularmente significativo nessa tese é o ajuste contínuo entre as convicções particulares e as aspirações coletivas gerais que acabam por determinar, de maneira ampla, as condutas a serem juridicamente protegidas, por isso aqueles que se identificam com o liberalismo político, como John Rawls e Ronald Dworkin, sustentam a importância de uma neutralidade do Estado no tocante à promoção de uma forma de vida substancial (good life) em particular sobre todas as demais ${ }^{8}$. Uma verdadeira implementação referente à tese da descontinuidade permitiria que todos tivessem o mesmo direito a expor suas convicções, abrindo-se deste modo também a réplicas e críticas ${ }^{9}$. Essa relevância é trabalhada pela autora da seguinte forma:

A tese da descontinuidade demanda que nós separemos nossos conceitos individuais acerca do bom daquilo que podemos impor a todos como uma questão de direito, consideradas nossa igualdade como pessoas... A separação do direito do bem é crucial para o reconhecimento da nossa igualdade como pessoas precisamente por causa das nossas profundas convicções acerca do que é bom para nós sexualmente pode nos colocar em direção ao pensamento que a nossa forma é a única maneira (Tradução do próprio autor) ${ }^{10}$.

8 Cf. NASON, Sarah. Practical-Political Jurisprudence and the Dual Nature of Law. Ratios Juris, v. 26, n. 3, 2013, p. 445 e ss.

9 Cf. BADER, Veit. Democratic inclusion in polities and governance arrangements. p. 571.

10 CORNELL, Drucilla. At the Heart of Freedom: Feminism, Sex and Equality. Princeton: Princeton University Press, 1998, p. 176 e ss. 
Compreender que a nossa maneira não é a única envolve o ajuste contínuo apontado pelo juízo reflexivo kantiano, mas é também a base da reelaboração que Cornell fará do ideal de liberdade. Essa abordagem será sensível, dentre outras coisas, às diversas maneiras pelas quais as minorias foram sufocadas em formações sociais que, pretendendo concretizar o ideal de igualdade social, tornaram-se severamente repressivas, a exemplo da União Soviética. Entretanto, é preciso evitar também o reducionismo de uma concepção de liberdade pensada tão somente em termos de referenciais econômicos e/ou em garantias jurídicas que mantenham reduzidas as intervenções estatais na sociedade civil.

A liberdade da qual Cornell fala se associa especificamente com as diversas maneiras pelas quais os indivíduos organizam e reorganizam os seus projetos existenciais particulares, considerando que, para a autora, o tornar-se pessoa é um projeto contínuo e aberto, onde o hiato entre aquilo que se é hoje e os potenciais futuros não admite fechamento definitivo, tal como ela observara também no juízo reflexivo kantiano. Se ser pessoa é processo, então é também algo situado para além da circunstância atual na qual os indivíduos se encontram: é projeção de aspirações, sonhos e crenças que vão sendo reorganizadas e ressignificadas conforme se vai vivendo. Em The Imaginary Domain, a autora aponta essa dimensão elusiva da pessoa, especialmente quando distingue a mesma de concepções pautadas por certas propriedades que tendem a ser permanentes ou ao menos contínuas. Escreve a autora:

A pessoa, neste entendimento, não seria alguma coisa que estaria "aí", mas a possibilidade, uma aspiração que, dada a sua natureza, jamais poderá ser preenchida de uma vez por todas. A pessoa, em outras palavras, está em um processo interminável de trabalhar através da personae. Nesta definição, a pessoa não será nem idêntica ao eu nem ao tradicional sujeito filosófico (Tradução do próprio autor $)^{11}$.

Sendo a pessoa um processo interminável e uma projeção futura dos indivíduos, a autora chama atenção para as condições subjacentes que não só permitem o desdobramento desse processo, como também são inerentes a ele: alguém só pode se tornar pessoa, isto é, perseguir as suas aspirações em meio a uma constante reflexão em torno do que lhe é existencialmente mais valioso, a partir de um conjunto de disposições normativas enraizadas na comunidade ${ }^{12}$. Em síntese, é necessário que se façam presentes no panorama institucional condições mínimas de individualização, o que, conforme a autora, somente é viável através da igualdade de direitos e da proteção institucional do domínio imaginário.

11 CORNELL, Drucilla. The Imaginary Domain: Abortion, Pornography and Sexual Harassment. London: Routledge, 1995, p. 5 e ss.

12 CORNELL, Drucilla. Beyond Accommodation: Ethical Feminism, Deconstruction, and the Law. New York: Rowman \& Littlefield Publishers, 1999, p. xxv e ss. 
O conceito de domínio imaginário, então, é empregado por Cornell ao tratar das múltiplas formas e dimensões pelas quais os indivíduos se reconstroem continuamente como pessoas. Contempla disposições sociais, afetivas, psicológicas, tendências conscientes ou inconscientes, associando tanto as referências simbólicas quanto materiais. O que está em questão no conceito é uma delicada articulação entre igualdade e liberdade. A igualdade se expressa ao menos em duas tendências: primeiro, no tratamento institucional que será legado a todos os cidadãos, principalmente concedendo a cada um mesmo conjunto de direitos fundamentais; segundo, reconhecendo que, apesar das diferenças que podem ser significativas entre esses grupos, eles possuem potencialidades similares. Discorrendo sobre a relação, profunda, entre o domínio imaginário e a sexualidade, Cornell destaca:

A noção do domínio imaginário reconhece que o espaço literal não se confunde com o espaço psíquico e revela que o nosso sentimento de liberdade está intimamente associado à renovação da imaginação na medida em que confrontamos quem nós somos e quem gostaríamos de ser enquanto seres sexualizados. Uma vez que, psicanaliticamente, o imaginário é inseparável do imago sexual da pessoa, ele demanda que ninguém seja forçado a ter um outro imaginário imposto sobre si mesmo de maneira a lhe usurpar o próprio respeito enquanto ser sexualizado (Tradução do próprio autor) ${ }^{13}$.

Para que um outro imaginário não seja imposto, o imaginário inicial cultivado pelo indivíduo precisa lhe permitir vislumbrar formas de vidas que lhe levem a ser respeitado e considerado pelos seus pares. É nesse processo de reconhecimento que se permite aos indivíduos renovarem a imaginação e colocarem em prática projetos existenciais desenvolvidos a partir das suas próprias opções ao invés de refletirem as escolhas predominantes. Uma concepção forte de democracia, que pode ser chamada de radical, exige que os espaços institucionais sejam montados de tal forma a permitir e fortalecer o pluralismo de concepções em torno do que seria uma vida decente. O ponto de partida é que cada indivíduo, em sua singularidade, precisa a priori receber igual consideração e respeito através das práticas sociais coletivamente compartilhadas na comunidade, ponto estabelecido com insistência e sólidos argumentos por Dworkin ${ }^{14}$.

Se um casal de lésbicas carece de um reconhecimento jurídico de sua união, o que por si só produz consequências importantes para as áreas de direito de família, de sucessões e mesmo para fins previdenciários, isso também significa uma apreciação valorativa presente nas instituições: a união delas é de menor valor quando considerada perante as demais e isso quando, a rigor, já não seria por si só considerada uma anormalidade. Neste cenário os arranjos sociais contribuem para a adoção de um imaginário familiar heterossexual que tende a estabelecer severas dificuldades para aqueles que,

13 CORNELL, Drucilla. The Imaginary Domain: Abortion, Pornography and Sexual Harassment. p. 8.

14 Cf. DWORKIN, Ronald. Justice for Hedgehogs. Cambridge: Harvard University Press, 2011, p. 379 e ss; FAGELSON, David. Justice as Integrity: Objectivity and Social Meaning in Legal Theory. Social \& Legal Studies, v. 11 , n. 4,2002 , p. 573 e ss. 


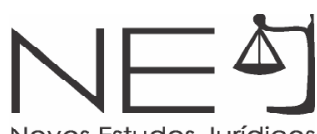

a princípio, não pretendem cultivar a sua sexualidade nesta direção. A proteção jurídica, mais especificamente constitucional, do domínio imaginário existe a partir de um entrelaçamento da liberdade com a igualdade tendo em vista que a manifestação das inclinações individuais, o que se reflete na liberdade de redefinir e pôr em prática um dado projeto existencial, precisa de um suporte institucional que permita esse exercício. A desigualdade, seja ela em termos materiais ou em termos de reconhecimento simbólico, é um dos fatores que dificulta, senão coloca em severo risco, a autonomia para seguir as suas aspirações e projetos inicialmente desenvolvidos a partir do próprio imaginário.

Por essas razões, o tratamento discriminatório pelo Estado, considerando o igual conjunto de direitos partilhados entre os cidadãos, precisa ser devidamente justificado, especificando qual elemento receberá esse tratamento e quais as razões para que ele seja concedido à luz dos valores que norteiam as democracias liberais. Em síntese, é preciso ver como esse tratamento fortalece os segmentos escolhidos e quais seriam os déficits e impedimentos presentes no caso de não concessão do tratamento.

\section{PROTEGENDO AS CONDIÇÕES DE INDIVIDUALIZAÇÃO: O DOMÍNIO IMAGINÁRIO E OS DIREITOS FUNDAMENTAIS}

Uma das preocupações de Cornell, e que precisa integrar também qualquer reflexão crítica acerca da dinâmica das instituições em sociedades democráticas, reside em considerar as mais diversas formas de distorções que criem barreiras tanto para o desenvolvimento das potencialidades individuais quanto da construção dos projetos existenciais de cada um: se as normas jurídicas ignoram o tratamento desigual referente ao gêneros, a exemplo da remuneração desigual que homens e mulheres recebem ao desempenharem as mesmas funções, então as normas estão atuando na reprodução dessas mesmas desigualdades, sendo inclusive elementos que as validam.

A materialização da igualdade em meio às práticas sociais e a forma com que as instituições operam, como também no mercado de trabalho e em outros domínios da sociedade civil, passa pela implementação de um conjunto de direitos responsáveis por proteger essa equivalência. Aliás, se existe um fato de difícil contestação, é o de que nos momentos fundantes da sociedade, naqueles em que politicamente são determinadas as suas bases, faz-se presente sempre uma certa desigualdade de poder entre os participantes e aqueles que serão afetados por essas decisões ${ }^{15}$. Discutir a igualdade, em tese, é também um exercício de autorreflexão sobre o momento fundante da comunidade e os arranjos de poder que dificultam mudanças. Cornell destaca:

Eu argumentei em outro lugar que nós precisamos de um programa de direitos equivalentes para as mulheres se sequer pretendermos começar a estabelecer a fundamentação jurídica para a igualdade das mulheres. Utilizo a palavra fundamentação porque não estou sugerindo que a igualdade entre homens e mulheres é apenas, e principalmente, uma questão de direitos. Ainda assim

15 Cf. CORDERO, Rodrigo. Giving society a form: Constituent moments and the force of concepts. Constellations, v. 26,2019 , p. 2 e ss. 
"direitos" expressam uma realidade tanto simbólica quanto social. Os símbolos, por sua vez, não podem ser separados das construções sociais mais amplas e multifacetadas a que nós chamamos de sociedade (Tradução do próprio autor) ${ }^{16}$.

Um aspecto relevante na promoção dos direitos fundamentais reside na maneira como simultaneamente eles tendem a refletir os ideais valorativos de uma coletividade e a permitir uma progressiva individualização dos projetos existenciais de cada um. O direito como o de liberdade religiosa, então, permite que as convicções, crenças e orientações particulares dos indivíduos encontrem meios de se concretizarem e de serem também vividas em espaços institucionalizados. Para além disso, objetiva garantir que o Estado e terceiros venham a respeitar as práticas e valores que norteiam as convicções religiosas de cada um. A ausência desse direito pode - e normalmente é isso que tende a ocorrer - impedir alguns grupos sociais de publicamente exercerem a sua fé.

Uma vez ancorado em ideais abertos a múltiplas interpretações e inserções nos mais variados discursos que pretendem organizar o social, os direitos fundamentais não raro constituem zonas de conflito nas quais grupos com ideais concorrentes terminam por entrar em rota de colisão. Recorrendo à filosofia política de Carl Schmitt e às considerações de Michael Oakeshott referentes à importância das práticas tradicionais subjacentes ao desenvolvimento histórico das comunidades, a teórica política belga Chantal Mouffe desenvolveu uma concepção de democracia agonística que, embora não associada diretamente aos direitos fundamentais, ainda pode contribuir para a elaboração de uma análise dos direitos fundamentais atrelada às pretensões críticas de Cornell ${ }^{17}$.

Mouffe desenvolve o seu conceito de agonismo em contraposição ao de antagonismo tendo como pano de fundo as democracias liberais contemporâneas, especialmente após o momento histórico subsequente à queda da União Soviética. Se a consolidação do capitalismo liberal intensificou ainda mais a sua expansão global, também se multiplicam os focos de conflito em torno do reconhecimento simbólico de identidades e demandas, como também em formas que promovam maiores participações das classes sociais na riqueza coletiva da sociedade ${ }^{18}$.

O conflito entre projetos políticos concorrentes não admite, segundo Mouffe, soluções tecnológicas ancoradas em uma perspectiva neutra: insistir em soluções como essa significa desconsiderar o papel dos afetos e do imaginário que conduz e ampara os projetos políticos ${ }^{19}$. Aceitando a tese da descontinuidade tal como Cornell a compreende, Mouffe, no entanto, ressalta a importância não somente a importância dos valores que tradicionalmente constituíram a comunidade,

16 CORNELL, Drucilla. The Philosophy of the Limit: Systems Theory and Feminist Legal Reform. In: CORNELL, Drucilla; ROSENFELD, Michel; CARLSON, David Gray (orgs). Deconstruction and the Possibility of Justice. London: Routledge, 1992, pp. 68-69.

17 Cf. MOUFFE, Chantal. Agonistics: Thinking the World Politically. London: Verso, 2013; MOUFFE, Chantal. On the Political. London: Routledge, 2005, p. 8 e ss.

18 Cf. CONNOLLY, William E. The Ethos of Pluralization. 4. ed. Minneapolis: University of Minnesota Press, 2004, p. 77 e ss.

19 Cf. MOUFFE, Chantal. The Return of the Political. London: Verso, 1993, p. 93 e ss; MOUFFE, Chantal. On the Political. p. 25 e ss. 


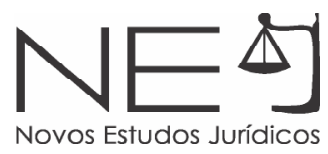

como insiste em que o significado mesmo desses valores se encontra em disputa. Qualquer tentativa de fixar, de uma vez por todas e para além de qualquer conflito, um único sentido para o bem comum significa retornar para uma concepção pré-moderna de política, pondo em risco o pluralismo ${ }^{20}$.

Recorrendo às considerações de Claude Lefort ${ }^{21}$ (LEFORT, 1988, p. 17 e ss) sobre a sociedade moderna, Chantal Mouffe reitera o vazio constitutivo do bem comum culminando na impossibilidade de atrelar a ele um sentido último, único e permanente. De maneira semelhante ao que Cornell observara no juízo reflexivo kantiano e em seu senso comum estético, o vazio expõe à sociedade moderna a uma contínua redefinição dos valores e referenciais que normativamente vão caracterizar formas de vida consideradas adequadas. Sobre a sociedade moderna, então, escreve Mouffe:

Neste tipo de sociedade já não se é possível proporcionar uma garantia última, uma legitimação definitiva, porque associada a uma posição transcendental. Poder, direito e conhecimento são, então, expostos a uma indeterminação radical: na minha concepção, um bem comum substancial se torna impossível

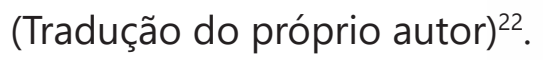

A ausência de uma garantia última intervém diretamente na compreensão e também operacionalização dos direitos fundamentais nas democracias liberais. Se a normatividade jurídica demanda, ao menos em termos institucionais, uma certa permanência de sentido que lhe concede generalidade, os valores mesmos que informam esses direitos estão sendo constantemente confrontados e redefinidos pelas transformações, normalmente imprevisíveis, do social. É razoável sustentar - e parece ser essa a posição sustentada por Mouffe - que os sentidos dos direitos fundamentais dependem diretamente do projeto político que então se faz hegemônico em um dado espaço social. Uma vez considerado o vazio constitutivo da sociedade moderna mencionado por Lefort, os sentidos atribuídos aos direitos fundamentais em função dos projetos hegemônicos estabelecidos só podem ser provisórios e instáveis: o domínio ontológico do político é precisamente aquele em que as grandes cisões serão estabelecidas, como justo/injusto, normal/patológico e mesmo real/imaginário 23 .

A argumentação de Mouffe pode proporcionar um respaldo teórico significativo ao conceito de domínio imaginário e sua relação com os direitos fundamentais pelo menos em alguns pontos. O primeiro deles, mais complexo, refere-se à relação entre os direitos fundamentais, o vazio constitutivo da sociedade e o conceito de pessoa empregado por Cornell, sendo também uma referência importante para o seu conceito de domínio imaginário. Em At The Heart of Freedom, a autora escreve: "o domínio imaginário é o espaço do "e se" em que nós imaginamos quem podemos

20 Cf. BOBBIO, Norberto. Estado, Governo, Sociedade: Para uma teoria geral da política. 14. ed. Paz e Terra, 2007, p. 152 e ss.

21 Cf. LEFORT, Claude. Democracy and Political Theory. Cambridge: Polity Press, 1988, p. 17 e ss.

22 MOUFFE, Chantal. The Return of the Political. p. 62.

23 Cf. CORDERO, Rodrigo. Giving society a form: Constituent moments and the force of concepts. p. 4 e ss. 
ser se nos vermos como fins em si mesmos, apropriando a nossa própria pessoa"24. É isso que pode ser discernido nas diversas revoltas que percorreram o mundo árabe há alguns anos: a busca por um novo imaginário social capaz de redefinir o sentido de nação e povo, trazendo implicações consideráveis para a participação popular ${ }^{25}$.

Em um interessante artigo sobre um tema correlato, o da política prefigurativa, Paul Raekstad explora pontualmente a distância entre a práxis e a visão, entre as ações efetivas que podem ser tomadas e o horizonte futuro no qual mudanças podem ser vislumbradas, trazendo deste modo a motivação para se intervir no presente, tomando cuidado para que o processo escolhido não seja dissociado do resultado almejado ${ }^{26}$. Essa visão não necessariamente precisa estar amparada em uma rigorosa fundamentação racional: o decisivo é que ela seja forte o suficiente para que se leve à ação. Uma visão de uma sociedade na qual as distorções presentes tenham sido resolvidas, mas que não proporcione o ímpeto para a transformação e proteção daquilo que, hoje, pode propor essas mudanças, acaba por se tornar vazia.

Essa dimensão imaginária mantém em aberto as múltiplas formas de redefinição pelas quais os indivíduos avaliam suas vidas e situações em função do que poderiam ser e do que melhor lhes satisfaz em termos de projetos de vida. Seu exercício, no entanto, ocorre sempre a partir do pano de fundo mais amplo e normativamente regulado da comunidade, e é em parte com o propósito de assegurar e manter este plano que os direitos fundamentais surgem. Tal como ocorre com a dimensão imaginativa no nível particular, calcada no autoexame que os indivíduos realizam acerca de suas opções e projetos, também a comunidade pode realizar esse autoexame mediante a concorrência dos projetos hegemônicos que visam apreender e fixar o sentido, inclusive operacional, dos direitos fundamentais e dos valores políticos básicos da comunidade.

Considerando a definição usual de direitos fundamentais como formas de proteção e garantia inscritas na norma constitucional, é muito razoável discernir nos valores que trazem consigo - vida, educação, liberdade, igualdade, privacidade, dentre outros - elementos que permitem atrelar projetos políticos, com a sua visão mais ampla e relativamente indeterminada do que seria uma sociedade correta e adequada, e elementos institucionais que já se mostram consolidados nos espaços da política e do direito. É nos embates entre projetos distintos que não somente novas concepções do social podem surgir, como também, ao lado delas, considerações alternativas sobre formas de se proteger o domínio imaginário. Essa dimensão valorativa que firmemente associa os direitos fundamentais localizados aos direitos humanos universais, é bem captada por Gianluigi Palombella quando escreve:

A determinação dos direitos humanos e dos direitos fundamentais deve obedecer

24 CORNELL, Drucilla. At the Heart of Freedom: Feminism, Sex and Equality. p. 8.

25 Cf. CHALLAND, Benoit. The Counter-Power of Civil Society and the Emergence of a New Political Imaginary in the Arab World. Constellations, v. 18, n. 3, 2011, p. 279 e ss.

26 Cf. RAEKSTAD, Paul. Revolutionary practice and prefigurative politics: A clarification and defense. Constellations, v. 25,2018 , p. 363 e ss. 
a critérios de caráter ético e político; no que se refere aos direitos humanos, normalmente os ordenamentos ocidentais têm sido depósitos de juízo de valor que foram consolidados ao longo dos últimos dois séculos. Deste modo tem sido formado e se segue formando catálogos mais ou menos compartilhados e mais ou menos difundidos de direitos humanos (PALOMBELLA, 1999, p. 526) ${ }^{27}$.

Se Cornell insiste na importância da igualdade, principalmente de condições, como pressuposto sem o qual não pode haver o domínio imaginário, a igualdade também é a ponte que permite associar este conceito com a formação da sociedade moderna através do que Lefort, seguindo as análises feitas por Aléxis de Tocqueville da sociedade norte-americana, vai chamar de revolução democrática. Dentre outros pontos, a expressão aponta para uma expansão da igualdade em domínios que outrora eram caracterizados por formas persistentes de desigualdade. Em síntese, se inicialmente os preceitos democráticos se concentram nas organizações perceptíveis da vida política, a exemplo do direito ao voto e da escolha pelos representantes políticos, aos poucos eles passam a integrar outras esferas. Discorrendo sobre essa leitura de Tocqueville, Lefort observa:

Muito embora ele tenha pretendido localizar o princípio fundamental da democracia no estado social - a igualdade de condições - ele explora a mudança em cada direção, interessando-se pelos laços sociais e instituições políticas, no indivíduo, nos mecanismos da opinião pública, nas formas de sensibilidade e formas de conhecimento, na religião, direito, linguagem, literatura, história, etc ${ }^{28}$.

Se a revolução democrática desloca a igualdade para áreas que lhe eram estranhas, esse processo não é nem espontâneo, nem passivamente aceito: a igualdade de condições abre espaço para a problematização de fatores e relações naturalizadas, comprometendo privilégios e vantagens, e por isso mesmo produz tensões e conflitos. Essa contraposição permite, por sua vez, não somente questionar a extensão de direitos já estabelecidos, como formas de autorrepresentação que se encontram vinculadas ao exercício desses direitos. A problematização e o confrontamento com o que existe é parte da busca pela construção de um novo imaginário social, e as mencionadas revoltas ocorridas em países árabes confirmam essa direção ${ }^{29}$.

Cria-se deste modo um desequilíbrio na maneira como os diversos imaginários são concebidos pelos segmentos díspares do social. Cornell enfatiza como o não reconhecimento da diferença sexual, por exemplo, permitiu um exercício desigual do direito à autorrepresentação por homens de elite e pelas mulheres. O exercício limitado, por sua vez, historicamente comprometeu de maneira severa a representação social das mulheres, especialmente no que se refere à sua participação política

27 PALOMBELLA, Gianluigi. Derechos Fundamentales: Argumentos Para Una Teoría. Revista Doxa, v. 22, 1999, p. 526.

28 LEFORT, Claude. Democracy and Political Theory. Cambridge: Polity Press, 1988, p. 14.

29 Cf. CHALLAND, Benoit. The Counter-Power of Civil Society and the Emergence of a New Political Imaginary in the Arab World, p. 278 e ss. 
e ao reconhecimento institucional das suas demandas. Em síntese, a maneira pela qual grupos determinados podem usufruir e liberar o seu imaginário guarda sintonia profunda com a maneira pela qual os direitos podem ser conquistados e observados. Quanto a este ponto, a autora tece o seguinte comentário:

Certamente homens de elite tiveram há muito concedido o seu direito à autorrepresentação - mesmo se exprimido como um direito a passar para um bem maior - enquanto essencial ao reconhecimento de que quem eles são, em algumas culturas como indivíduo, em outras como membros de um grupo religioso, nacional ou racial. As revoluções burguesas do Ocidente concederam o direito ao voto aos homens apenas porque supostamente eles tinham a capacidade para a autorrepresentação. Mulheres, por outro lado, durante muito tempo foram julgadas como tendo tão somente uma imaginação passiva e a habilidade de imitar a persona feminina considerada apropriada para as mulheres (Tradução do próprio autor) ${ }^{30}$.

A citação acima configura a ideia principal desta seção: os direitos fundamentais guardam uma profunda relação com o domínio imaginário, servindo também para compor o pano de fundo no qual as aspirações, expectativas e projetos existenciais podem ser postos em prática, como também permitem aos indivíduos, através desse processo, cultivarem as suas habilidades e sensibilidades de maneira que simultaneamente integrem uma comunidade e que lhe seja resguardado o que lhe há de mais específico e insubstituível.

\section{A NECESSÁRIA E DIFÍCIL BUSCA POR NOVOS IMAGINÁRIOS: DIREITOS FUNDAMENTAIS E A CONSTRUÇÃO POLÍTICA DO SOCIAL}

Se as democracias contemporâneas são marcadas por um elevado grau de fragmentação de demandas e múltiplos focos de antagonismo, ao ponto de ser particularmente difícil vislumbrar um sujeito coletivo que toma para si o trabalho de uma transformação radical do social, de que maneira os direitos fundamentais podem ser utilizados para fortalecer e expandir o repertório de garantias estabelecidas, introduzindo espaços para o cultivo de novos imaginários? Em outras palavras, o cerne da pergunta se encontra em conceber e desenvolver o potencial político dos direitos fundamentais apontados na seção anterior.

A insistência de Cornell na igualdade como elemento indispensável para a caracterização do domínio imaginário, por mais fecundas que sejam as consequências jurídicas desse valor, encontra-se atrelada a um outro valor, talvez até mais importante, e que também será central para o desdobramento político das sociedades modernas: a autonomia. Seja no âmbito individual, que o conceito de domínio imaginário acaba por reiterar, seja no coletivo, a autonomia aponta para um processo de construção no qual o futuro surge como espaço experimental e o passado, na forma

30 CORNELL, Drucilla. At the Heart of Freedom: Feminism, Sex and Equality. Princeton: Princeton University Press, 1998, p. 11. 
das tradições, já não mais delimita e restringe o horizonte dessas mudanças. Se as lutas políticas apontadas por Mouffe pretendem também fixar o significado e a extensão dos direitos fundamentais positivos, a tensão estabelecida entre o jogo de forças termina por expressar, ainda que de maneira inconsciente, o processo de construção coletiva do social através do exercício da autonomia. Individual e coletiva estão articuladas, como Cornell apontara: se o desdobramento da personalidade se encontra intimamente atrelado às condições institucionais que envolvem os indivíduos, não deixa de ser razoável sustentar uma associação as duas formas de desenvolvimento, individual e coletiva. Um teórico político cujas considerações sobre essa temática permanecem esclarecedoras, ainda que menções a ele não sejam recorrentes na obra de Cornell: trata-se de Cornelius Castoriadis.

Castoriadis é importante para a discussão desta temática pelo reforço que faz do entrelaçamento entre o individual e o coletivo, fundamental para o domínio imaginário: os indivíduos são produzidos pelas instituições em conformidade com normas estabelecidas as quais, de alguma maneira, serão perpetuadas $^{31}$. Indivíduo e coletivo se entrelaçam na reprodução e na ruptura da ordem social ${ }^{32}$. A filosofia política de Castoriadis tem como principal pretensão reconsiderar a noção de autonomia em meio a uma reconsideração da democracia em termos de seu potencial emancipatório ${ }^{33}$. Um ponto importante é a maneira pela qual ele desarticula a autonomia de uma dimensão utópica irrealizável e que cujos vestígios, de maneira um tanto quanto sutil, ainda permanecem na filosofia jurídicopolítica de Cornell. O autor pontualmente esclarece essa desarticulação da seguinte forma:

Utopia significa algo que nunca existiu e nem pode existir. O que eu chamo de projeto revolucionário, o projeto da autonomia individual e coletiva (os dois são inseparáveis) não é utopia, mas um projeto sócio-histórico suscetível de ser implementado, e que nunca foi provado que era impossível. A sua realização depende tão somente da atividade lúcida dos indivíduos e das pessoas, da sua compreensão, determinação e imaginação (Tradução do próprio autor) ${ }^{34}$.

Castoriadis proporciona um pano de fundo teórico no qual as pretensões de Cornell se articulam com as preocupações de Mouffe. Se, por um lado, a autora enfatiza o vazio constitutivo da sociedade para afirmar uma concepção agonística de democracia na qual a construção das identidades coletivas necessariamente repousa em projetos políticos contingentes, por outro lado é nesse processo conflituoso que valores como liberdade e igualdade serão atrelados - ou desatrelados - às visões de sociedades que vão adquirir forma nesse processo. A autonomia da qual fala o autor, de maneira muito semelhante ao modo como Cornell associa igualdade e domínio imaginário, tem em seu cerne a igualdade de participação no que diz respeito às atividades básicas da estrutura social, como legislar, governar e julgar. Rejeita-se a submissão a qualquer princípio determinístico e que impõe um curso

31 Cf. CASTORIADIS, Cornelius. The Imaginary. In: CASTORIADIS, Cornelius. World in Fragments: Writings on politics, society, psychoanalysis and the imagination. Stanford: Stanford University Press, 1997, p. 7 e ss.

32 Cf. DEWS, Peter. Imagination and the Symbolic: Castoriadis and Lacan. Constellations, v. 9, n. 4, pp. 516-521, 2002, p. 517 e ss.

33 Cf. KALYVAS, Andreas. Norm and Critique in Castoriadis's Theory of Autonomy. Constellations, v. 5, n. 2, 1998, p. 162 e ss.

34 CASTORIADIS, Cornelius. A Society Adrift - Interviews \& Debates (1974-1997). New York: Fordham University Press, 2010, p. 3 e ss. 
pré-determinado para o desenrolar dos acontecimentos no processo de constituição do social ${ }^{35}$. Chegar nesse estágio requer mudanças significativas no que diz respeito ao funcionamento das atuais instituições. Na filosofia política de Castoriadis o termo 'revolução' é empregado de maneira a aludir as transformações profundas pelas quais as instituições necessitam passar rumo a uma expansão da autonomia nos espaços sociais ${ }^{36}$. Tais transformações em muito se distanciam daquelas imagens associadas às revoluções francesas e soviéticas, marcadas por mobilizações violentas e uma destruição radical da estrutura política vigente. Se Castoriadis fala em radicalidade, assim o faz para distinguir a sua proposta daquela nomeada por ele de oligarquia liberal ${ }^{37}$.

Embora guardando certa aproximação com a pós-política pensada por Mouffe, a oligarquia liberal se refere à absorção do imaginário capitalista pela população, que restringe o potencial da vida humana à expansão ilimitada do consumo, da produção e da busca pelo bem-estar material. Um dos principais efeitos desse imaginário reside em afastar a população da vida política. Os poucos atos associados à política se convertem em rituais a serem reproduzidos sem suscitarem maiores indagações: o eleitor vota em candidatos que desconhece, almejando solucionar problemas que não entende: ao final desse processo, o distanciamento é mantido e o sistema continua a funcionar mantendo a população à deriva ${ }^{38}$.

O confrontamento com a oligarquia liberal rumo a uma formação política democrática centrada na autonomia exige, para Castoriadis, uma articulação entre três domínios que, conforme o autor, são constitutivos da vida social: a esfera privada, a esfera pública, e o espaço indeterminado do público/ privado. As duas primeiras esferas foram articuladas por Cornell em termos kantianos através do bem e do justo. Uma democracia que se caracteriza pela autonomia precisa de algum modo manter uma articulação entre esses três eixos. Se Cornell havia apontado o perigo da sobreposição do bem sobre o justo, Castoriadis observa que em regimes totalitários as três esferas se fundem enquanto que nas oligarquias liberais o que se tem é a prevalência de uma lógica inscrita na esfera público/privada, como o mercado ou a economia ao mesmo tempo em que se reduz o caráter especificamente público que residiria na esfera pública: tem-se uma forma de "delegação informal" em que a população abre mão de participar nas questões da comunidade para que os tecnocratas que tanto receio causam a Mouffe desempenhem essa função.

Se a preocupação de Cornell tem seu foco na extensão da igualdade de direitos fundamentais para os cidadãos, essa extensão somente vai se materializar na realidade social quando também a igualdade de participação nas questões públicas for confrontada, como lembra Castoriadis ${ }^{39}$. Essa igualdade será restringida, por vezes de maneira intensa, a depender da maneira como certas áreas do social vão ser organizadas.

35 Cf. STAVRAKAKIS, Yannis. Creativity and its Limits: Encounters with Social Constructionism and the Political in Castoriadis and Lacan. Constellations, v. 9, n.4, 2002, p. 517 e ss.

36 Cf. CASTORIADIS, Cornelius. A Society Adrift - Interviews \& Debates (1974-1997). p. 3 e ss; CASTORIADIS, Cornelius. The Imaginary Institution of Society. Cambridge: Polity Press, 1998, p. 95 e ss.

37 Cf. CASTORIADIS, Cornelius. A Society Adrift - Interviews \& Debates (1974-1997). p. 3 e ss.

38 Cf. CASTORIADIS, Cornelius. A Society Adrift - Interviews \& Debates (1974-1997). p. 4 e ss.

39 Cf. CASTORIADIS, Cornelius. A Society Adrift - Interviews \& Debates (1974-1997). p. 5 e ss. 
Um mundo laboral caracterizado por sobrejornadas constantes, salários que não permitem adquirir o básico e insegurança contínua dos vínculos laborais introduz barreiras significativas para que a partição mencionada por Castoriadis possa se converter em uma realidade. Novamente, tratase de uma questão sensível para Cornell: ao destacar a desconsideração da diferença sexual e as implicações causadas para as mulheres, Cornell ressalta, no tocante ao mercado de trabalho, os múltiplos entraves e obstáculos presentes que impedem a ascensão econômica e o reconhecimento profissional das mulheres ${ }^{40}$. Em direção semelhante, Castoriadis observa:

...uma sociedade democrática é claramente incompatível com a enorme concentração econômica atual. É também igualmente incompatível com o pseudo-planejamento burocrático. Existe também a questão da liberdade do trabalho. Os cidadãos não podem ser escravos do seu lugar de trabalho cinco ou seis dias por semana e livres nos domingos políticos (Tradução do próprio

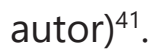

Seja pela intensa dependência da relação laboral, seja por não haver acesso ao mercado de trabalho, a maneira como os recursos materiais da sociedade é distribuída permite ou impede a concretização da igualdade mencionada por Castoriadis e Cornell. Se a desigualdade econômica contribui para proporcionar uma conformidade com o status quo, a ruptura e uma transformação radical que coloque diante de si a difícil tarefa de compor um novo imaginário social precisa desarticular o indivíduo do sistema, ou seja, é preciso que ele enxergue, naquilo que lhe é dado, seja na forma de direitos ou de projetos políticos, expectativas futuras que podem ser atualizadas desde que haja paixão, compromisso e estratégias para tanto.

Se o domínio imaginário depende de uma estrutura institucional ancorada na distribuição igualitária de direitos fundamentais, sendo especialmente sensível à diferença sexual há muito ignorada nas sociedades ocidentais, essa estrutura, por sua vez, como se pode depreender das considerações feitas por Castoriadis, encontra-se vinculada à autonomia individual e coletiva ${ }^{42}$. Quanto mais existirem entraves para que a coletividade se componha autonomamente, mais difícil será pôr em práticas as condições institucionais que vão permitir aos diversos indivíduos seguirem os seus projetos particulares. Essa seria a contribuição pontual de Castoriadis ao desenvolvimento teórico deste tema: o individual se conecta e se constrói em meio ao coletivo - e vice-versa ${ }^{43}$.

Pois bem, as transformações que visam a trazer a igualdade para esferas distintas e diversas, a revolução democrática tal como denominada por Lefort, não serão aceitas sem resistência e foi neste ponto que as colocações de Mouffe sobre agonismo e democracia radical foram importantes: na medida em que os grupos minoritários desenvolvem as suas demandas, eles assim o fazem através de interpretações dos principais valores que caracterizam a dinâmica institucional dessas comunidades - e é nesse processo em que parte das lutas se desenvolvem.

40 Cf. CORNELL, Drucilla. Beyond Accommodation: Ethical Feminism, Deconstruction, and the Law. p. $x$ e ss.

41 CASTORIADIS, Cornelius. A Society Adrift - Interviews \& Debates (1974-1997). p. 5 e ss.

42 Cf. CASTORIADIS, Cornelius. The Imaginary Institution of Society. p. 107 e ss.

43 Cf. CASTORIADIS, Cornelius. The Imaginary Institution of Society. p. 108 e ss. 
A luta de grupos femininos em prol da liberalização do aborto, por exemplo, reflete-se e fundamenta-se, ainda que em parte, em uma reflexão pontual sobre a autonomia feminina, principalmente no que diz respeito à autonomia sobre o seu próprio corpo. Nesta linha de reflexão, a proibição do aborto significa também reforçar a intervenção estatal sobre a autonomia feminina, os seus direitos reprodutivos, também impondo barreiras à implementação dos seus projetos existenciais.

Embora exista uma dimensão que é inequivocamente ética no conceito de domínio imaginário estabelecido por Cornell, o artigo ressalta que é importante justapor a essas considerações uma abordagem teórica que transita pelas diferentes maneiras com que os conflitos políticos terminam por moldar e propagar o domínio imaginário. Ainda que a tese da descontinuidade traga consigo uma consideração ética na qual as diferenças precisam encontrar acolhimento em um espaço institucional ancorado na igualdade, a imposição de uma forma de vida sobre a outra não é um simples gesto político, mas reflexo de um projeto hegemônico mais abrangente, no qual as instituições são cúmplices e reprodutoras.

\section{CONSIDERAÇÕES FINAIS}

Os direitos fundamentais trazem consigo não somente novas proteções e formas de resolução de conflitos de interesses, como em sua totalidade expressam uma certa imagem de sociedade tomada como referencial normativo. Uma das pretensões principais do artigo fora a de apontar algumas maneiras pelas quais o conceito de domínio imaginário de Drucilla Cornell trazer consequências significativas para a justificação de certas configurações institucionais, mais especificamente a articulação entre liberdade e igualdade no horizonte das democracias liberais, assim como a proteção às formas de vida das populações vulneráveis.

O conceito aponta para os diversos vetores pelos quais os indivíduos ao longo de suas vidas vão construindo e reconstruindo não somente projetos existenciais, como a maneira como se percebem enquanto indivíduos e também o papel que ocupam na comunidade em que se encontram. A imaginação abre o espaço entre o que se é e o que se pode e se pretende ser, tanto no nível individual quanto coletivo.

Conforme Cornell, a proteção do domínio imaginário abrange, dentre outros pontos, a nãoimposição de um imaginário sobre o outro, o que implicaria forçar a adesão de uma forma de vida a indivíduos que possuem concepções e sensibilidades distintas das mesmas. Essa imposição seria aquilo que, neste artigo, fora discutido em termos de identificação do bom e do justo, ou seja, conceber convicções particulares, específicas dos indivíduos, em termos de orientações gerais as quais podem ser impostas aos membros da coletividade. O oposto disso - e o que Cornell considera fundamental para que o domínio imaginário seja assegurado - é a descontinuidade, ao invés da identidade, entre o bom e o justo: é preciso fixar barreiras entre convicções particulares e 
orientações gerais para que haja uma conciliação entre liberdade e igualdade. Essa conciliação pode ser promovida e amparada mediante um conjunto de direitos fundamentais igualmente distribuídos entre os cidadãos, permitindo-os perseguir os seus mais diversos projetos, rechaçando formas de tratamento discriminatório que visem a dificultar - ou mesmo impedir - a implementação desses projetos. Sem a igualdade, a liberdade é prejudicada e se torna esvaziada uma vez que os anseios individuais não vão encontrar em espaços para serem respeitados e concretizados na comunidade.

A maneira pela qual Castoriadis aborda a autonomia, principalmente em sua relação com o imaginário e com as formas de constituição do social, torna-se relevante para o desenvolvimento dessa pesquisa ao apontar a relação circular e interdependente entre indivíduo e coletividade. Deste modo o conceito de domínio imaginário pode - e deve ser - pensado a partir do pano de fundo institucional que lhe cerca (os espaços do direito e da política) e, por sua vez, este pano de fundo pode ser transformado através das diversas ações indivíduos que refletem a busca pela concretização de projetos existenciais ainda não reconhecidos.

Se o domínio imaginário é pensado como um direito por Cornell, a sua existência depende da construção de um projeto político no qual as instituições jurídicas sejam sensíveis às diferentes metas e perspectivas dos indivíduos, o que exige um processo de luta contínua contra aqueles que almejam sobrepor as suas convicções perante os demais. Essa sobreposição não se reflete apenas na rejeição da tese da descontinuidade, mas na implementação de um projeto hegemônico que desestrutura, tanto no nível do reconhecimento simbólico quanto no da distribuição material dos recursos gerados coletivamente pela comunidade, grupos considerados de menor importância e tratados como cidadãos de segunda classe.

O projeto de uma democracia agonística permitiria a Cornell desenvolver mais as diversas formas pelas quais os embates políticos moldam, expandem ou contraem as possibilidades de defesa do domínio imaginário e, por tabela, da capacidade de que cada indivíduo tenha de ressignificar a sua vida e os valores recepcionados. Os direitos fundamentais podem se constituir em instrumentos importantes para a proteção das prerrogativas mencionadas por Cornell, mas precisam ser encarados como elementos que ganham significado e operacionalidade a partir de sua interseção em projetos políticos específicos determinados.

\section{REFERÊNCIAS DAS FONTES CITADAS}

BADER, Veit. Democratic inclusion in polities and governance arrangements. Constellations, v. 25, pp. 570585, 2018.

BOBBIO, Norberto. A Era dos Direitos. Rio de Janeiro: Campus, 1992.

BOBBIO, Norberto. Estado, Governo, Sociedade: Para uma teoria geral da política. 14. ed. Paz e Terra, 2007. 
CASTORIADIS, Cornelius. A Society Adrift - Interviews \& Debates (1974-1997). New York: Fordham University Press, 2010.

CASTORIADIS, Cornelius. The Imaginary Institution of Society. Cambridge: Polity Press, 1998.

CASTORIADIS, Cornelius. The Imaginary. In: CASTORIADIS, Cornelius. World in Fragments: Writings on politics, society, psychoanalysis and the imagination. Stanford: Stanford University Press, 1997.

CHALLAND, Benoit. The Counter-Power of Civil Society and the Emergence of a New Political Imaginary in the Arab World. Constellations, v. 18, n. 3, pp. 271-283, 2011.

CONNOLLY, William E. The Ethos of Pluralization. 4. ed. Minneapolis: University of Minnesota Press, 2004. CORDERO, Rodrigo. Giving society a form: Constituent moments and the force of concepts. Constellations, v. 26, pp. 1-14, 2019.

CORNELL, Drucilla. At the Heart of Freedom: Feminism, Sex and Equality. Princeton: Princeton University Press, 1998.

CORNELL, Drucilla. Beyond Accommodation: Ethical Feminism, Deconstruction, and the Law. New York: Rowman \& Littlefield Publishers, 1999.

CORNELL, Drucilla. Defending Ideals: War, Democracy, and Political Struggles. London: Routledge, 2004.

CORNELL, Drucilla. Enlightening the Enlightenment: A Response to John Brenkman. Critical Inquiry, v. 26, n. 1, pp. 128-139, 1999.

CORNELL, Drucilla. The Imaginary Domain: Abortion, Pornography and Sexual Harassment. London: Routledge, 1995.

CORNELL, Drucilla. The Philosophy of the Limit: Systems Theory and Feminist Legal Reform. In: CORNELL, Drucilla; ROSENFELD, Michel; CARLSON, David Gray (orgs). Deconstruction and the Possibility of Justice. London: Routledge, 1992, pp. 68-94.

DEWS, Peter. Imagination and the Symbolic: Castoriadis and Lacan. Constellations, v. 9, n. 4, pp. 516-521, 2002.

DWORKIN, Ronald. Justice for Hedgehogs. Cambridge: Harvard University Press, 2011.

FAGELSON, David. Justice as Integrity: Objectivity and Social Meaning in Legal Theory. Social \& Legal Studies, v. 11, n. 4, p. 569-588, 2002.

KALYVAS, Andreas. Norm and Critique in Castoriadis's Theory of Autonomy. Constellations, v. 5, n. 2, pp. 161-182, 1998.

LEFORT, Claude. Democracy and Political Theory. Cambridge: Polity Press, 1988.

MOUFFE, Chantal. Agonistics: Thinking the World Politically. London: Verso, 2013.

MOUFFE, Chantal. On the Political. London: Routledge, 2005.

MOUFFE, Chantal. The Return of the Political. London: Verso, 1993.

NASON, Sarah. Practical-Political Jurisprudence and the Dual Nature of Law. Ratios Juris, v. 26, n. 3, pp. 430455, 2013.

NERGELIUS, Joakin. Derecho y Democracia. Revista Doxa, v. 8, pp. 309-318, 1990. 
PALOMBELLA, Gianluigi. Derechos Fundamentales: Argumentos Para Una Teoría. Revista Doxa, v. 22, pp. 525-579, 1999.

RAEKSTAD, Paul. Revolutionary practice and prefigurative politics: Aclarification and defense. Constellations, v. 25, p. 359-372, 2018.

STAVRAKAKIS, Yannis. Creativity and its Limits: Encounters with Social Constructionism and the Political in Castoriadis and Lacan. Constellations, v. 9, n.4, pp. 522-539, 2002.

Recebido em: 29/04/2020

Aprovado em: $13 / 11 / 2020$ 